\title{
Overexpression of $\mathrm{CLC}-3$ is regulated by $\mathrm{XRCC} 5$ and is a poor prognostic biomarker for gastric cancer
}

Zhuoyu Gu ${ }^{1,2+}$, Yixin Li ${ }^{3 \dagger}$, Xiaoya Yang ${ }^{2,4+}$, Meisheng Yu ${ }^{1,2}$, Zhanru Chen ${ }^{4}$, Chan Zhao ${ }^{4}$, Lixin Chen ${ }^{*}$ and Liwei Wang ${ }^{4^{*}}$ (D)

\begin{abstract}
Background: Recently, many potential prognostic biomarkers for gastric cancer (GC) have been identified, but the prognosis of advanced GC patients remains poor. Chloride channels are promising cancer biomarkers, and their family member chloride channel-3 (CLC-3) is involved in multiple biological behaviors. However, whether CLC-3 is a prognostic biomarker for GC patients is rarely reported. The molecular mechanisms by which CLC-3 is regulated in GC are unclear.
\end{abstract}

Methods: The expression of CLC-3 and XRCC5 in human specimens was analyzed using immunohistochemistry. The primary biological functions and pathways related to CLC-3 were enriched by RNA sequencing. A 5'-biotinlabeled DNA probe with a promoter region between -248 and +226 was synthesized to pull down CLC-3 promoter-binding proteins. Functional studies were detected by MTS, clone formation, wound scratch, transwell, and xenograft mice model. Mechanistic studies were investigated by streptavidin-agarose-mediated DNA pulldown, mass spectrometry, ChIP, dual-luciferase reporter assay system, Co-IP, and immunofluorescence.

Results: The results showed that CLC-3 was overexpressed in human GC tissues and that overexpression of CLC-3 was a poor prognostic biomarker for $\mathrm{GC}$ patients $(P=0.012)$. Furthermore, higher expression of $C L C-3$ was correlated with deeper tumor invasion $(P=0.006)$ and increased lymph node metastasis $(P=0.016)$, and knockdown of $C L C-3$ inhibited cell proliferation and migration in vitro. In addition, X-ray repair cross-complementing 5 (XRCC5) was identified as a CLC-3 promoter-binding protein, and both CLC-3 (HR 1.671; 95\% Cl 1.012-2.758; $P=0.045)$ and XRCC5 (HR 1.795; 95\% Cl 1.076-2.994; $P=0.025$ ) were prognostic factors of overall survival in GC patients. The in vitro and in vivo results showed that the expression and function of CLC-3 were inhibited after XRCC5 knockdown, and the inhibition effects were rescued by CLC-3 overexpression. Meanwhile, the expression and function of CLC-3 were promoted after XRCC5 overexpression, and the promotion effects were reversed by the CLC-3 knockdown. The mechanistic study revealed that knockdown of XRCC5 suppressed the binding of XRCC5 to the CLC-3 promoter and subsequent promoter activity, thus regulating CLC-3 expression at the transcriptional level by interacting with PARP1.

Conclusions: Our findings indicate that overexpression of $\mathrm{CLC}-3$ is regulated by XRCC5 and is a poor prognostic biomarker for gastric cancer. Double targeting CLC-3 and XRCC5 may provide the promising therapeutic potential for GC treatment.

Keywords: CLC-3, XRCC5, Prognosis, Biomarker, Gastric cancer

\footnotetext{
*Correspondence: tchenlixin@jnu.edu.cn; twangliwei@jnu.edu.cn

${ }^{\dagger}$ Zhuoyu Gu, Yixin Li and Xiaoya Yang contributed equally to this work.

'Department of Pharmacology, Medical College, Jinan University, Guangzhou

510632, China

${ }^{4}$ Department of Physiology, Medical College, Jinan University, Guangzhou

510632, China

Full list of author information is available at the end of the article
}

(c) The Author(s). 2018 Open Access This article is distributed under the terms of the Creative Commons Attribution 4.0 International License (http://creativecommons.org/licenses/by/4.0/), which permits unrestricted use, distribution, and reproduction in any medium, provided you give appropriate credit to the original author(s) and the source, provide a link to the Creative Commons license, and indicate if changes were made. The Creative Commons Public Domain Dedication waiver (http://creativecommons.org/publicdomain/zero/1.0/) applies to the data made available in this article, unless otherwise stated. 


\section{Background}

Gastric cancer (GC), the second leading cause of cancer-related death worldwide, is characterized by advanced clinical stages at diagnosis and poor survival rates [1, 2]. In 2012, GC accounted for $6.8 \%$ of global cancer incidence and $8.8 \%$ of cancer mortality worldwide [3]. GC development is a complicated multistep process, influenced by a Helicobacter pylori infection, host genetic susceptibility, and other environmental factors [4]. Achieving a detailed understanding of the molecular pathogenesis associated with GC will be critical to improving patient outcomes. Recently, many potential prognosis biomarkers for GC have been identified, including BMI1, Ezh2, and LINC00261 [5-8]. However, the prognosis of advanced GC remains poor. Therefore, the identification of further biomarkers for therapeutic purposes in GC is imperative.

Chloride channels are promising cancer biomarkers by mediating a multitude of biological functions [9]. Chloride channel-3 (CLC-3), a member of the voltage-gated chloride channel family, mainly mediates the extra- and intracellular ion homeostasis and acidification of intracellular compartments. Recent studies have revealed that CLC-3 participates in the processes of cell volume regulation, proliferation, and migration, particularly in glioma and prostate cancer cells [10-12]. Our previous studies have indicated that CLC-3 is overexpressed in nasopharyngeal carcinoma cells and plays roles in controlling cell proliferation [13]. Moreover, suppression of CLC-3 expression reduces the migration of nasopharyngeal carcinoma, hepatocellular carcinoma, and cervical carcinoma cells [14-16]. Therefore, CLC-3 may play key roles in tumor development. However, whether CLC-3 is a prognostic biomarker for GC patients is rarely reported. The molecular mechanisms by which CLC-3 is regulated in GC are unclear.

Our present study indicated that overexpression of CLC-3 was a poor prognostic marker for GC patients and that cell proliferation and migration were the primary biological functions of CLC-3 in GC cells. Moreover, XRCC5, a subunit of the $\mathrm{Ku}$ heterodimer protein $[17,18]$, was identified to be a promoter-binding protein of CLC-3. As a key mediator of DNA recombination, chemotherapy resistance, and chromosome stability maintenance [19-21], XRCC5 has elevated expression in a variety of tumors [22-24]. However, little is known about the expression of XRCC5 in GC. In this study, we showed that XRCC5 was highly expressed in GC. Importantly, the expression and function of CLC-3 were regulated by XRCC5 in vivo and in vitro, and both CLC-3 and XRCC5 were prognostic factors of overall survival in GC patients. The relative expressions of CLC-3 and XRCC5 could determine the further prognosis of GC patients.

\section{Methods}

\section{Patient samples}

Paraffin-embedded tumor tissues and adjacent normal tissues were obtained from 90 patients diagnosed with gastric adenocarcinoma between May 2007 and February 2008 at the First Affiliated Hospital of Zhengzhou University. Medical records of all patients provided information about age, gender, pathological grade, and TNM stage. The patients were followed up for 8 years. Written informed consent was obtained from each patient involved in the study, and the study was approved by the Ethics Committee of Zhengzhou University.

\section{Cell culture and stable cell line construction}

Human GC cell lines (SGC-7901, BGC-823, and AGS) and human normal gastric epithelial (GES-1) cells were obtained and authenticated from the Cell Bank of the Chinese Academy of Sciences (Shanghai, China). All cells were cultured in RPMI 1640 medium supplemented with $10 \%$ fetal bovine serum. Lentiviruses for XRCC5 knockdown (shXR-1 and shXR-2), XRCC5 overexpression (XRCC5), CLC-3 knockdown (shCLC-3), and CLC-3 overexpression (CLC-3) were purchased from GenePharma (Shanghai, China). SGC-7901 and BGC-823 cells were used to establish stable cell lines via selection with $1 \mu \mathrm{g} /$ $\mathrm{ml}$ puromycin for 4 weeks. Negative control shRNA cells (sh-NC) and empty vector-transfected cells (vector) were established as controls.

\section{Streptavidin-agarose-mediated DNA pull-down assay}

A biotin-labeled double-stranded oligonucleotide probe for the -248 to +226 fragment of the CLC-3 promoter sequence was synthesized by Ruibiotech Co. (Beijing, China). Briefly, $1 \mathrm{mg}$ of nuclear protein extract was mixed and incubated with $10 \mu \mathrm{g}$ of probe and $100 \mu \mathrm{l}$ of streptavidin-agarose beads (Sigma, St Louis, MO). The mixtures were then centrifuged at $800 \times g$, resuspended in $30 \mu \mathrm{l}$ of loading buffer, and boiled at $100{ }^{\circ} \mathrm{C}$ for $5 \mathrm{~min}$. The collected samples containing the bound proteins were separated by SDS-PAGE for further silver staining or Western blot analysis.

\section{Silver staining and mass spectrometry}

After electrophoresis of the samples containing the bound proteins, the protein gel was immersed in a stationary liquid with $10 \%$ acetic acid, $50 \%$ ethanol, and $40 \%$ water at room temperature on a shaker overnight. The protein bands were visualized with a fast silver staining kit (Beyotime, Shanghai, China) and analyzed using MS by Honortech (Beijing, China).

\section{Chromatin immunoprecipitation assay}

The chromatin immunoprecipitation (ChIP) procedure was performed as illustrated in the ChIP kit (cat\# 9002S, 
Cell Signaling Technology, Danvers, MA). Briefly, the tested cell lines were fixed with formaldehyde, and cross-linking was performed by adding glycine. The samples were placed on ice and sonicated to separate the DNA into 100 to 1000-bp fragments. Then, they were incubated with antibodies at a dilution of 1:50 overnight, followed by incubation with protein $\mathrm{G}$ agarose beads at $4{ }^{\circ} \mathrm{C}$ overnight. Next, the bound DNA-protein mixtures were eluted, and cross-linking was reversed after several washes. The DNA fragments were then purified, and PCR was performed with CLC-3 primers purchased from GeneCopoeia (cat\# HQP001983, Rockville, MD, USA) to amplify a 102-bp segment. The PCR products were separated on $2 \%$ agarose gels and visualized on a UV transilluminator.

\section{Dual-luciferase reporter assay}

The pGL4.13 vector was used as a positive control for the luciferase reporter system. Fragments including the CLC-3 promoter region were inserted between the HindIII and KpnI sites of the pGL4.10 luciferase vector (Promega, Madison, WI). Primer pairs were designed for the truncated promoter regions, as shown in Additional file 1: Table S1. Briefly, stable cell lines were plated in 96-well plates and transfected with luciferase plasmid. To normalize the transfection efficiency, the cells were co-transfected with the Renilla luciferase control reporter pRL-TK vector by using EndoFectin ${ }^{\text {Tw }}$ Max (GeneCopoeia, Inc.). Luciferase activity was detected using the Dual-Luciferase ${ }^{\circ}$ Reporter Assay System (Promega) after $48 \mathrm{~h}$.

\section{RNA extraction and quantitative RT-PCR}

Total RNA was extracted from cells using a RaPure Total RNA Micro Kit (Magen, Guangzhou, China). Endogenous cDNA was obtained by the ReverTra Ace qPCR RT Master Mix kit (Toyobo, Shanghai, China). Primers for CLC-3 (cat\# HQP001983), XRCC5 (cat\# HQP018568), and GAPDH (cat\# HQP006940) were obtained from GeneCopoeia Inc. Finally, qRT-PCR was performed with SYBR $^{\circ}$ Green Real-time PCR Master Mix (Toyobo) in a Bio-Rad CFX96 PCR system. Relative RNA levels were calculated as the fold changes with the $2^{-\Delta \Delta \mathrm{CT}}$ formula.

\section{Co-immunoprecipitation (Co-IP) assay and Western blot analysis}

Protein extracts were prepared and incubated with antibodies against XRCC5 or IgG for $24 \mathrm{~h}$ on a rotating wheel. Then, Protein A/G plus-Agarose beads (Santa Cruz, Dallas TX, USA) were added and incubated for another $24 \mathrm{~h}$. After the beads were boiled, the precipitated proteins were separated by SDS-PAGE and transferred to PVDF membranes for further analysis. For
Western blot (WB) analysis, equal amounts of proteins from the lysates were separated and transferred. The membranes were blocked with 5\% nonfat milk for $2 \mathrm{~h}$ and then incubated with antibodies. The protein bands were finally detected by enhanced chemiluminescence. The density of the protein bands was quantified by ImageJ software (National Institutes of Health, Bethesda, MD) and normalized to GAPDH. Relative protein levels were calculated as the density ratios of interest protein to GAPDH. All antibodies used for WB were purchased from Cell Signaling Technology (Danvers, MA, USA).

\section{MTS assay and clone formation assay}

Cell proliferation was determined by MTS assays (Promega, Madison, WI). Different stable cell lines and stable cell lines transfected with PARP1 siRNA (GenePharma, Shanghai, China) were seeded at a density of 5000 cells per well in 96-well plates. At the time points of $24 \mathrm{~h}, 48 \mathrm{~h}$, and $72 \mathrm{~h}$ after seeding, the cells were respectively incubated with MTS for $40 \mathrm{~min}$, and the optical density (OD) was then detected with a microplate reader. For the clone formation assay, cells were seeded at a density of 500 cells per well in 6-well plates and cultured for 2 weeks. The formative colonies were then fixed with formalin and stained by crystal violet. The number of clones was counted by Image-Pro Plus 6.0 software.

\section{Wound scratch assay and transwell assay}

Cell migration ability was examined by the wound scratch assay. Briefly, cells were cultured in 6-well plates until reaching confluence and then were scratched with a $10-\mu \mathrm{l}$ pipette tip. The gap widths at $0 \mathrm{~h}(\mathrm{w} 1)$ and at 36 or $48 \mathrm{~h}$ (w2) were measured, and the relative migration rate was calculated as $(\mathrm{w} 1-\mathrm{w} 2) / \mathrm{w} 1 \times 100 \%$. Transwell assay was performed with Boyden chambers containing 24-well transwell plates (BD, Franklin Lakes, USA). Homogeneous single-cell suspensions were added to the upper chambers coated with Matrigel. After $24 \mathrm{~h}$, invaded cells on the bottom of the chambers were stained with crystal violet and counted in five random fields.

\section{RNA sequencing}

Briefly, samples (SGC-7901 cells transfected with control or CLC-3 shRNA) were used to extract total RNA for RNA-seq loading and quality control. Differential gene expression (DGE) RNA-seq was then performed, and 50-bp paired-end reads were finally produced (RiboBio, Guangzhou, China). NCBI Sequence Read Archive (SRA) sequencing data were submitted under accession number SRP135951. 


\section{In vivo tumor model}

All animal experimental procedures were approved by the Animal Care and Use Committee of Jinan University. Approximately $2 \times 10^{6}$ cells in $100 \mu \mathrm{l}$ of PBS were subcutaneously injected. Tumor volumes were recorded every 4 days and calculated according to the equation of volume $=\left(\right.$ width $^{2} \times$ length $) / 2$. After 4 weeks, the tumor xenografts were harvested, weighed, and processed for immunohistochemistry (IHC) staining.

\section{Immunofluorescence and immunohistochemistry}

Cells were first seeded onto coverslips in a 6-well plate. Subsequently, the cells were fixed with $4 \%$ paraformaldehyde, permeabilized with $0.5 \%$ Triton-X, and blocked with bovine serum albumin (BSA). The coverslips were then incubated with primary antibodies at a dilution of 1:200 overnight. After washing, the coverslips were incubated with secondary antibodies and stained with 4,6-diamidino-2-phenylindole (DAPI). The immunofluorescence images were captured by a confocal microscope (Olympus, Japan). For IHC staining, the paraffin-embedded sections were incubated with anti-XRCC5 and anti-CLC-3 primary antibodies at a dilution of 1:100 overnight. After washing, the sections were incubated with horseradish peroxidase-conjugated anti-goat antibodies and stained with 3,5-diaminobenzidine (DAB). The percentage of stained cells $(0-100 \%)$ was multiplied by the staining intensity $(0,1,2$, or 3$)$ to produce the final IHC scores (0-300), of which 100 or higher was considered to indicate high XRCC5 expression, and 60 or higher was considered to indicate high CLC-3 expression.

\section{Statistical analysis}

Statistical analyses were performed using SPSS statistical software. All data were presented as the mean \pm SD. The significance of difference was assessed by $t$ tests or variance analysis. Correlations between XRCC5 and CLC-3 expression were assessed using Spearman rank correlation analysis, and overall survival curves were assessed using Kaplan-Meier analysis. Multivariate cumulative survival analysis was conducted with the Cox regression model. The $P$ values less than 0.05 were considered statistically significant.

\section{Results}

Overexpression of CLC-3 was a poor prognostic biomarker for GC patients, and CLC-3 knockdown inhibited cell proliferation and migration in vitro

To confirm whether CLC-3 was a potential cancer biomarker for GC, in this study, we first examined the expression of CLC-3 in 90 paraffin-embedded GC tumor tissues and adjacent normal tissues (ANT) by IHC analysis. Significantly, the expression of CLC-3 was higher in GC tissues than that in ANT. Moreover, CLC-3 was mainly localized to the cell membrane and cytoplasm (Fig. 1a, b). Next, we analyzed the effect of CLC-3 expression on the cumulative survival rate of these $90 \mathrm{GC}$ patients. Kaplan-Meier analysis showed that high expression (IHC score $\geq 60$ ) of CLC-3 predicted poor survival outcome, indicating that CLC-3 overexpression was a poor prognostic biomarker for $\mathrm{GC}$ patients $(P=0.012$, Fig. 1c). Furthermore, we examined the relationship between the CLC-3 expression and the clinicopathological characteristics in GC patients. As shown in Table 1, higher CLC-3 expression was correlated with deeper tumor invasion $(P=0.006)$, increased lymph node metastasis $(P=0.016)$, and later clinical staging $(P=0.015)$.

We further investigated the role of CLC-3 in vitro. Basic protein expression of CLC-3 in human normal gastric epithelial cells (GES-1) and human GC cell lines (SGC-7901, BGC-823, and AGS) was detected by WB. The expression of CLC-3 was also increased in GC cell lines compared to that in normal cells (Fig. 1d). To identify the biological functions of CLC-3 in GC cells, the primary biological processes participated by CLC-3 were analyzed by RNA sequencing in SGC-7901 cells. The heatmap and volcano plot revealed that 136 and 175 genes (upregulated and downregulated, respectively) were differentially expressed after the CLC-3 knockdown. By Gene Ontology (GO) analysis of these differential genes, cell proliferation and migration were identified as the primary biological functions of CLC-3 (Fig. 1e). We then validated the effect of CLC-3 knockdown on cell proliferation and migration. Our results showed that knockdown of CLC-3 inhibited the proliferation of GC cells at different time points (Fig. 1f). Next, clone formation assay showed that knockdown of CLC-3 attenuated the clonogenicity of GC cells (Fig. 1g). Furthermore, the scratch assay and transwell assay indicated that knockdown of CLC-3 impaired the migration rate and number of invaded GC cells (Fig. 1h, i). To study the pathways related to CLC-3 in GC cells, Kyoto Encyclopedia of Genes and Genomes (KEGG) pathway enrichment was performed by RNA sequencing in SGC-7901 cells, and the PI3K/Akt signaling pathway was enriched as the primary pathway after CLC-3 knockdown (Fig. 1j). We then verified that knockdown of CLC-3 reduced the levels of key targets in the PI3K/ Akt signaling pathway, which revealed that CLC-3 knockdown inhibited this pathway (Fig. 1k). Altogether, our results proved that as a prognostic biomarker for GC, CLC-3 also had important functions in vitro.

\section{XRCC5 was identified as a CLC-3 promoter-binding protein, and both CLC-3 and XRCC5 were prognostic factors of overall survival in GC patients}

To explore the molecular mechanism of CLC-3 overexpression in GC cells, we further detected the basic RNA 


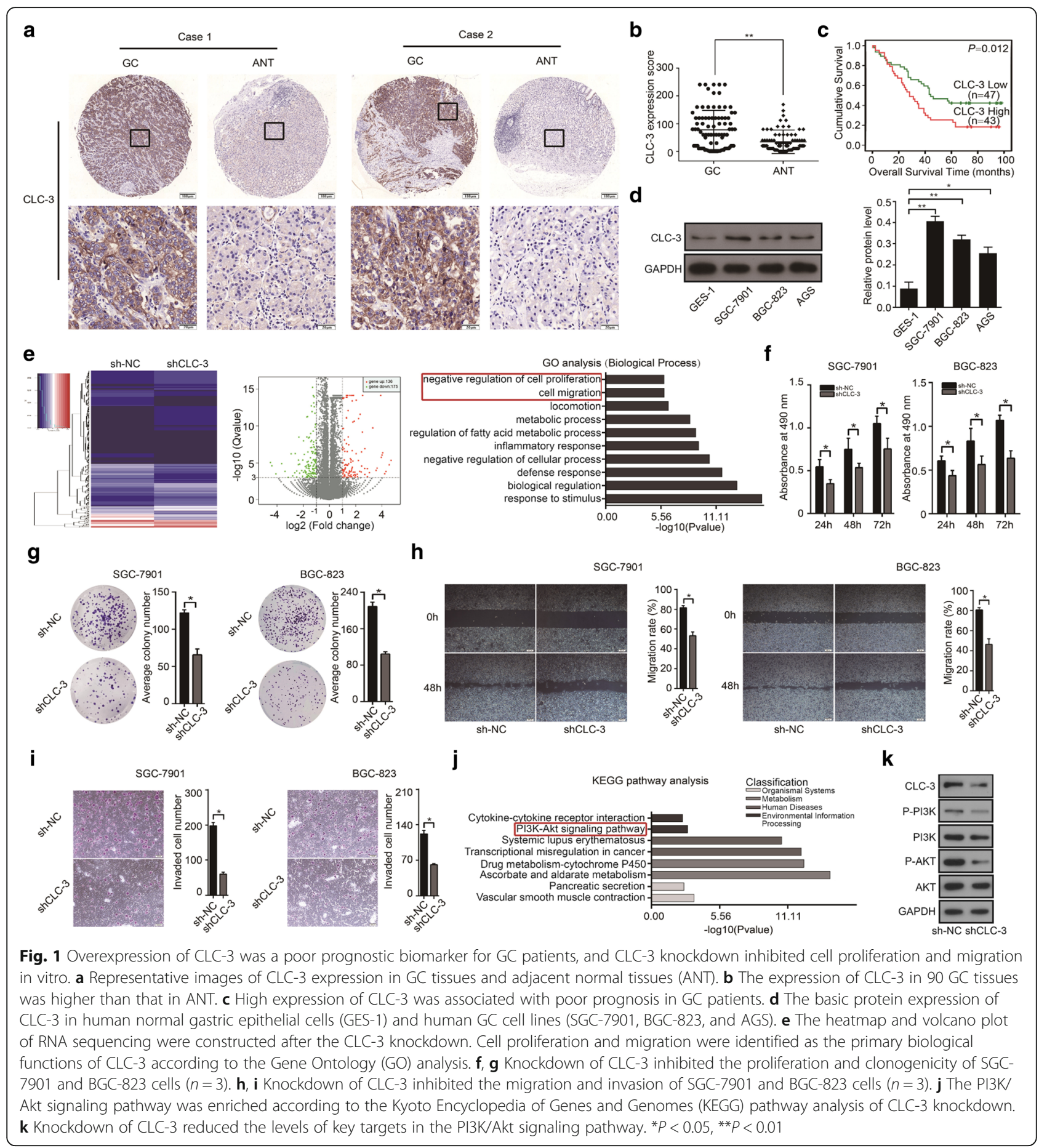

expression of CLC-3 in the above cell lines. The RNA level of CLC-3 was also elevated in GC cells compared to that in normal cells (Fig. 2a), suggesting that the CLC-3 overexpression might be regulated by some tumor-specific factors at the transcriptional level. To study the transcriptional regulatory mechanism of CLC-3 overexpression, a series of truncated CLC-3 gene promoter fragments were amplified by PCR and cloned into the pGL4.10-basic vector to construct dual-fluorescence reporter plasmids. The results of agarose gel electrophoresis indicated that each truncated fragment had the correct size in accordance with our designed sequence (Fig. 2b). Dual-luciferase reporter assays revealed that all reporter plasmids exhibited promoter activity in SGC-7901 cells, while the pGL4.10-CLC-3 - 248 
Table 1 Correlations between CLC-3 expression and clinicopathological characteristics of GC patients

\begin{tabular}{|c|c|c|c|c|c|}
\hline \multirow[t]{2}{*}{ Variables } & \multirow[t]{2}{*}{$N$} & \multicolumn{2}{|l|}{ CLC-3 } & \multirow[t]{2}{*}{$x^{2}$} & \multirow[t]{2}{*}{$P$ value } \\
\hline & & $\begin{array}{l}\text { Low } \\
\text { expression }\end{array}$ & $\begin{array}{l}\text { High } \\
\text { expression }\end{array}$ & & \\
\hline \multicolumn{6}{|l|}{ Age } \\
\hline$\leq 70$ & 55 & 29 & 26 & 0.014 & 0.904 \\
\hline$>70$ & 35 & 18 & 17 & & \\
\hline \multicolumn{6}{|l|}{ Gender } \\
\hline Male & 70 & 35 & 35 & 0.623 & 0.430 \\
\hline Female & 20 & 12 & 8 & & \\
\hline \multicolumn{6}{|c|}{ Pathological grade } \\
\hline$|/| \mid$ & 24 & 15 & 9 & 1.386 & 0.239 \\
\hline III/IV & 66 & 32 & 34 & & \\
\hline \multicolumn{6}{|c|}{ Depth of invasion } \\
\hline $\mathrm{T} 1 / \mathrm{T} 2$ & 11 & 10 & 1 & 7.517 & 0.006 \\
\hline $\mathrm{T} 3 / \mathrm{T} 4$ & 79 & 37 & 42 & & \\
\hline \multicolumn{6}{|c|}{ Lymph node metastases } \\
\hline NO & 23 & 17 & 6 & 5.826 & 0.016 \\
\hline $\mathrm{N} 1 / \mathrm{N} 2 / \mathrm{N} 3$ & 67 & 30 & 37 & & \\
\hline \multicolumn{6}{|c|}{ Distant metastasis } \\
\hline MO & 86 & 45 & 41 & 0.009 & 0.927 \\
\hline M1 & 4 & 2 & 2 & & \\
\hline \multicolumn{6}{|l|}{ TNM stage } \\
\hline$|/| \mid$ & 37 & 25 & 12 & 5.930 & 0.015 \\
\hline III/IV & 53 & 22 & 31 & & \\
\hline
\end{tabular}

CLC-3 chloride channel-3, GC gastric cancer

plasmid showed higher promoter activity combined with shorter sequence length, indicating that a 5 '-biotin-labeled DNA probe with a promoter region between -248 and + 226 was optimal to pull down CLC-3 promoter-binding proteins (Fig. 2c, d).

We synthesized and incubated this probe with nuclear protein extracts to pull down potential CLC-3 promoterbinding proteins. After SDS-PAGE and silver staining, the target protein band (at almost $86 \mathrm{kDa}$ ) was observed, and the amount of this protein band was significantly enriched in GC cells compared with normal cells (Fig. 2e, left; red rectangle). This protein band was then excised and analyzed by MS. With the best peptide-spectrum sequence of KYAPTEAQLNAVDALIDSMSLAK, XRCC5 was identified as a candidate binding to the CLC-3 promoter (Fig. 2e, right). To ascertain the binding between XRCC5 and the CLC-3 promoter, we pulled down the nuclear protein/DNA complex in GC cells using synthesized DNA probe or nonspecific probe (NSP) and validated their binding by WB (Fig. 2f). Furthermore, ChIP assays were performed to further confirm the binding of XRCC5 protein to CLC-3 DNA. We found that XRCC5 bound the CLC-3 DNA in all cells, while the smallest amount of binding was observed in normal cells (Fig. 2g).

We then explored the clinicopathologic significance of CLC-3 and XRCC5 in GC patients. IHC analysis revealed that XRCC5 was localized to the nucleus, and the expression of both CLC-3 and XRCC5 was higher in GC tissues than that in ANT. Moreover, by observing IHC images of the same site, we found that patients with strong XRCC5 staining tended to have strong CLC-3 staining (Fig. 2h, i). The Spearman rank correlation analysis showed that the expression of CLC-3 and XRCC5 was positively correlated $(r=0.369, P<0.001)$ (Fig. 2j). Next, the Kaplan-Meier survival analysis revealed that high expression (IHC score $\geq 100$ ) of XRCC5 predicted a poor prognosis for $\mathrm{GC}$ patients $(P<0.001$, Fig. $2 \mathrm{k})$. In addition, higher XRCC5 expression was correlated with deeper tumor invasion $(P=0.036)$ and later clinical staging $(P=0.045)$ (Table 2). Importantly, compared to those with low CLC-3 and high XRCC5 levels, the GC patients with high CLC-3 and low XRCC5 levels did not present a difference in overall survival $(P>0.05$, Fig. 2l). However, patients with high expression of XRCC5 and CLC-3 had the worst prognosis $(P<0.001$, Fig. $2 \mathrm{~m})$. To further check the prognostic value of CLC-3 and XRCC5, multivariate analysis was used to investigate the correlation between cumulative overall survival rates and clinicopathological characteristics. As shown in Table 3, four factors, including depth of invasion (hazard rate $(\mathrm{HR})=1.883 ; 95 \%$ CI $1.135-3.122 ; P=0.014)$, TNM stage $(\mathrm{HR}=2.349 ; \quad 95 \%$ CI $1.342-4.114 ; \quad P=0.003)$, XRCC5 expression $(\mathrm{HR}=1.795 ; 95 \%$ CI $1.076-2.994 ; P$ $=0.025)$, and CLC-3 expression $(\mathrm{HR}=1.671 ; 95 \% \mathrm{CI}$ $1.012-2.758 ; P=0.045$ ), were associated with the clinical outcomes of GC patients. Our results suggested that both CLC-3 and XRCC5 were prognostic factors of overall survival in GC patients.

\section{The expression and function of CLC-3 were regulated by XRCC5 in vitro}

To study the relationship between XRCC5 and CLC-3 in vitro, we established stable XRCC5-knockdown cell lines (SGC-7901 and BGC-823) and corresponding rescue models by transfecting lentivirus of CLC-3 overexpression. WB revealed that the expression of CLC-3 was inhibited after XRCC5 knockdown in SGC-7901 and BGC-823 cells, and the inhibition effect was rescued by CLC-3 overexpression (Fig. 3a, b). According to the primary biological functions of CLC-3, we investigated the effects of XRCC5 knockdown on cell proliferation and migration. The proliferation of GC cells was attenuated after XRCC5 knockdown, and the attenuation effect was rescued by CLC-3 overexpression (Fig. 3c, d). Furthermore, clone formation assay showed that knockdown of XRCC5 attenuated the cell clonogenicity. Similarly, the 


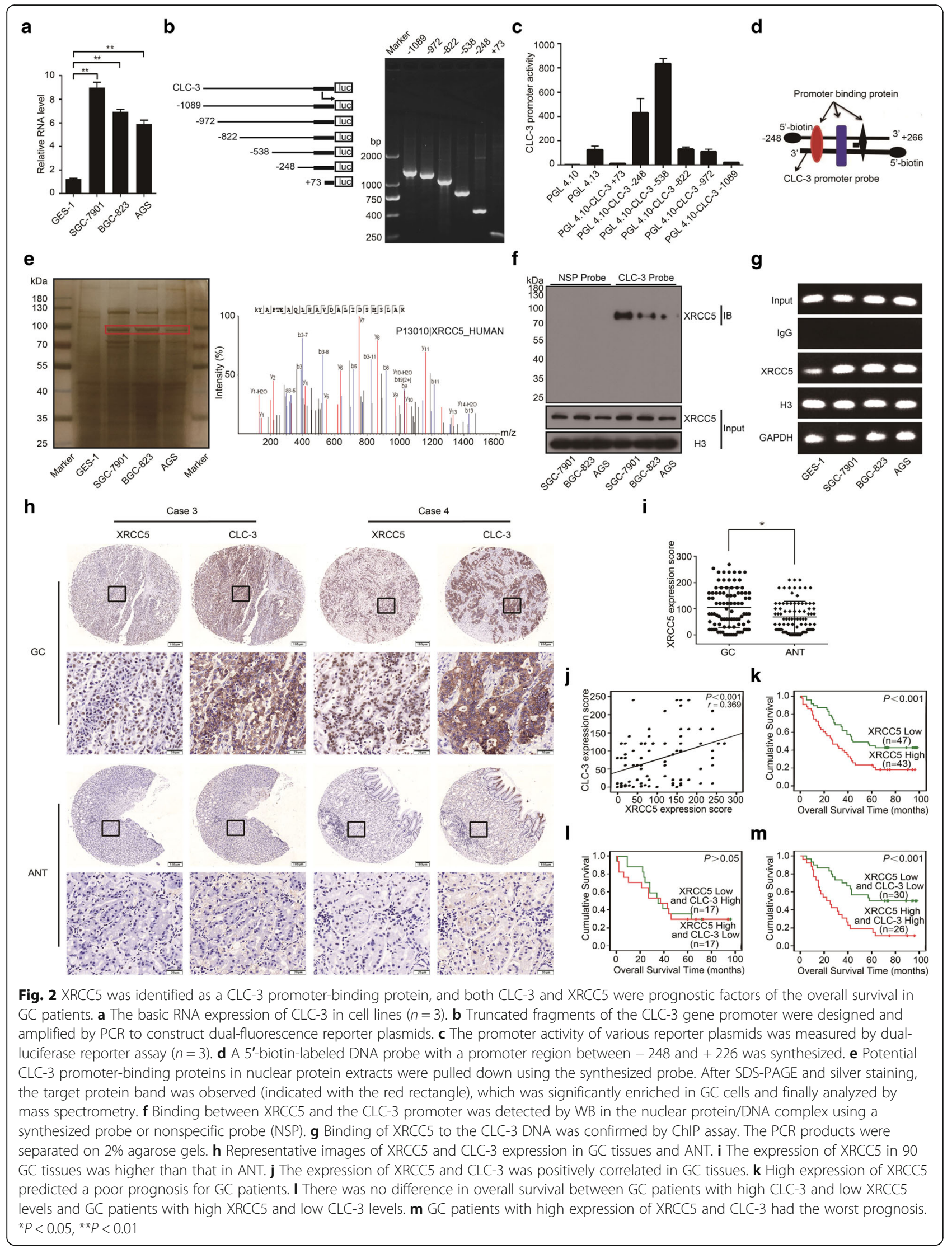


Table 2 Correlations between XRCC5 expression and clinicopathological characteristics of GC patients

\begin{tabular}{|c|c|c|c|c|c|}
\hline \multirow[t]{2}{*}{ Variables } & \multirow[t]{2}{*}{$N$} & \multicolumn{2}{|l|}{ XRCC5 } & \multirow[t]{2}{*}{$x^{2}$} & \multirow[t]{2}{*}{$P$ value } \\
\hline & & $\begin{array}{l}\text { Low } \\
\text { expression }\end{array}$ & $\begin{array}{l}\text { High } \\
\text { expression }\end{array}$ & & \\
\hline \multicolumn{6}{|l|}{$\overline{\text { Age }}$} \\
\hline$\leq 70$ & 55 & 33 & 22 & 3.429 & 0.064 \\
\hline$>70$ & 35 & 14 & 21 & & \\
\hline \multicolumn{6}{|l|}{ Gender } \\
\hline Male & 70 & 34 & 36 & 1.683 & 0.195 \\
\hline Female & 20 & 13 & 7 & & \\
\hline \multicolumn{6}{|c|}{ Pathological grade } \\
\hline$|/| \mid$ & 24 & 9 & 15 & 2.843 & 0.092 \\
\hline III/IV & 66 & 38 & 28 & & \\
\hline \multicolumn{6}{|c|}{ Depth of invasion } \\
\hline $\mathrm{T} 1 / \mathrm{T} 2$ & 11 & 9 & 2 & 4.399 & 0.036 \\
\hline $\mathrm{T} 3 / \mathrm{T} 4$ & 79 & 38 & 41 & & \\
\hline \multicolumn{6}{|c|}{ Lymph node metastases } \\
\hline NO & 23 & 14 & 9 & 0.926 & 0.336 \\
\hline $\mathrm{N} 1 / \mathrm{N} 2 / \mathrm{N} 3$ & 67 & 33 & 34 & & \\
\hline \multicolumn{6}{|c|}{ Distant metastasis } \\
\hline Mo & 86 & 46 & 40 & 1.243 & 0.265 \\
\hline M1 & 4 & 1 & 3 & & \\
\hline \multicolumn{6}{|l|}{ TNM stage } \\
\hline$|/| \mid$ & 37 & 24 & 13 & 4.025 & 0.045 \\
\hline III/IV & 53 & 23 & 30 & & \\
\hline
\end{tabular}

XRCC5 X-ray repair cross-complementing 5, GC gastric cancer

attenuation effect was rescued by CLC-3 overexpression (Fig. 3e, f). Next, scratch assay and transwell assays revealed that the migration and invasion of SGC-7901 and BGC-823 cells were also inhibited after XRCC5 knockdown, and the inhibition effects were rescued by CLC-3 overexpression (Fig. 3g, h).

To further evaluate whether CLC-3 was the target of XRCC5, we established stable cell lines with XRCC5 overexpression and corresponding reverse models by transfecting lentivirus of CLC-3 knockdown. The protein expression of CLC-3 in SGC-7901 and BGC-823 cells was increased after XRCC5 overexpression, and the increase effects could be reversed by CLC-3 knockdown (Fig. 4a, b). We then found that XRCC5 overexpression promoted the cell proliferation and clonogenicity, and these promotion effects could be reversed by CLC-3 knockdown (Fig. 4c-f). Scratch and transwell assays indicated that the migration and invasion of GC cells were enhanced by XRCC 5 overexpression. Similarly, these enhancement effects were reversed by CLC-3 knockdown (Fig. 4g, h). These findings confirmed that the expression and function of CLC-3 were regulated by XRCC5 in vitro.

\section{The expression of $\mathrm{CLC}-3$ was regulated at the transcriptional level by XRCC5 interacting with PARP1}

The significant association between CLC-3 and XRCC5 revealed in cellular experiments and clinical outcomes led us to further examine their underlying molecular mechanisms. ChIP assays indicated that the binding of XRCC5 to the CLC-3 DNA in SGC-7901 cells was suppressed after XRCC5 knockdown (Fig. 5a). Dual-luciferase reporter assays revealed that knockdown of XRCC5 impaired the promoter activities of the pGL4.10-CLC-3 - 248 and pGL4.10-CLC-3 - 538 reporter plasmids in SGC-7901 cells (Fig. 5b). We then detected RNA expression of CLC-3 in established stable cell lines. The RNA level of CLC-3 was inhibited after XRCC5 knockdown and increased after XRCC5 overexpression, validating that the expression of CLC-3 was regulated by XRCC5 at the transcriptional level (Fig. 5c). Based on the primary related pathway of CLC-3 indicated above, we assessed whether the PI3K/Akt signaling pathway was inhibited after XRCC5 knockdown. The results demonstrated that knockdown of XRCC5 reduced the levels of key targets in the PI3K/Akt signaling

Table 3 Multivariate analysis between cumulative overall survival rates and clinicopathological characteristics of GC patients

\begin{tabular}{lll}
\hline Variables & $H R(95 \%$ Cl) & $P$ value \\
\hline Age, $>$ 70 (vs. $\leq 70)$ & $1.734(0.650-4.628)$ & 0.271 \\
Gender, female (vs. male) & $1.069(0.589-1.940)$ & 0.827 \\
Pathological grade, III/IV (vs. I/II) & $1.260(0.661-2.401)$ & 0.483 \\
Depth of invasion, T3/T4 (vs. T1/T2) & $1.883(1.135-3.122)$ & 0.014 \\
Lymph node metastases, N1/N2/N3 (vs. N0) & $2.251(0.809-6.261)$ & 0.120 \\
Distant metastasis, M1 (vs. M0) & $1.480(0.815-2.687)$ & 0.198 \\
TNM stage, III/IV (vs. I/II) & $2.349(1.342-4.114)$ & 0.003 \\
XRCC5 expression, high (vs. low) & $1.795(1.076-2.994)$ & 0.025 \\
$C L C-3$ expression, high (vs. low) & $1.671(1.012-2.758)$ & 0.045
\end{tabular}




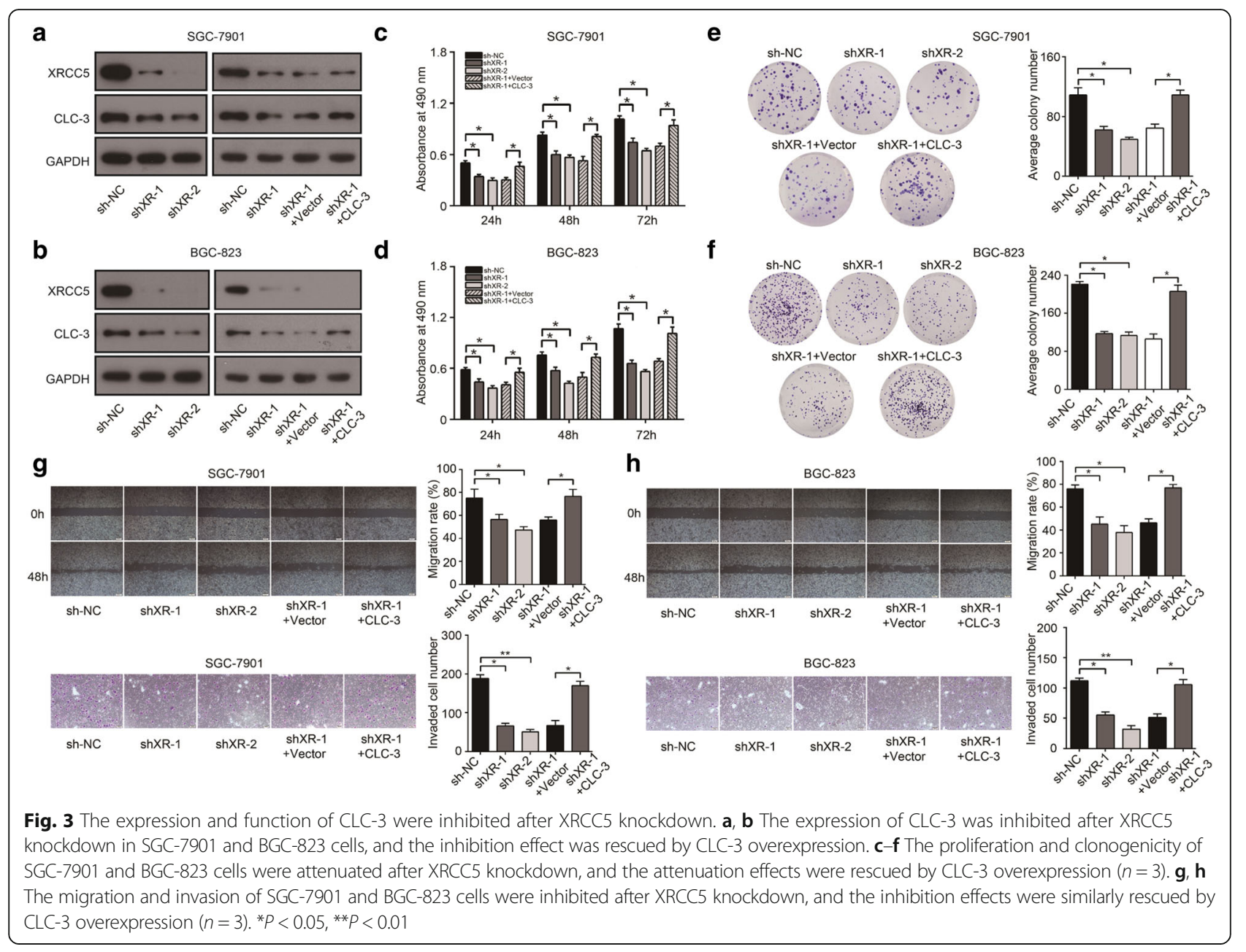

pathway by downregulating CLC-3 in SGC-7901 cells (Fig. 5d).

Next, to identify the interaction partners of XRCC5 in regulating the expression of CLC-3, we performed immunoprecipitation (IP) combined with mass spectrometry (MS) in nuclear protein extracts of SGC-7901 cells with anti-XRCC5 antibodies. The MS results showed that 12 proteins were potential candidates for interaction with XRCC5, of which PARP1 was found to have the highest confidence score and coverage percentage (Fig. 5e). The best peptide-spectrum sequences of PARP1 and XRCC5 were shown in Fig. 5f, g. Next, the interaction between XRCC5 and PARP1 was confirmed by Co-IP in stable SGC-7901 cells with XRCC5 overexpression (Fig. 5h). To certify whether PARP1 also bound to the CLC-3 promoter, we pulled down the nuclear protein/DNA complex in GC cells using a CLC-3 promoter probe or NSP and validated their binding by WB (Fig. 5i). In addition, the subcellular localization of XRCC5 and PARP1 was examined by confocal microscopy analysis. The obtained images indicated that XRCC5 (green) and PARP1 (red) were both primarily expressed in the nucleus, and the co-localization of XRCC5 and PARP1 was observed in the nucleus (yellow) (Fig. 5j). The effect of PARP1 interacting with XRCC5 on CLC-3 expression was then explored. Overexpression of XRCC5 increased the expression of CLC-3 in SGC-7901 cells, and the increase effect could be reversed by PARP1 knockdown (Fig. 5k). Functionally, the promotion effects of XRCC5 overexpression on cell proliferation and clonogenicity were also reversed by PARP1 knockdown (Fig. 5l, m). Overall, the results indicated that the expression and function of CLC-3 were regulated at the transcriptional level by XRCC5 interacting with PARP1.

\section{The expression and function of CLC-3 were regulated by XRCC5 in vivo}

The association between XRCC5 and CLC-3 was also investigated in mouse xenograft models. SGC-7901 cells were subcutaneously injected into the left flank of nude mice. Tumor volumes were measured and recorded every 4 days. After approximately 4 weeks, the tumor xenografts were harvested, weighed, and processed for IHC staining. Our observations revealed that tumor 


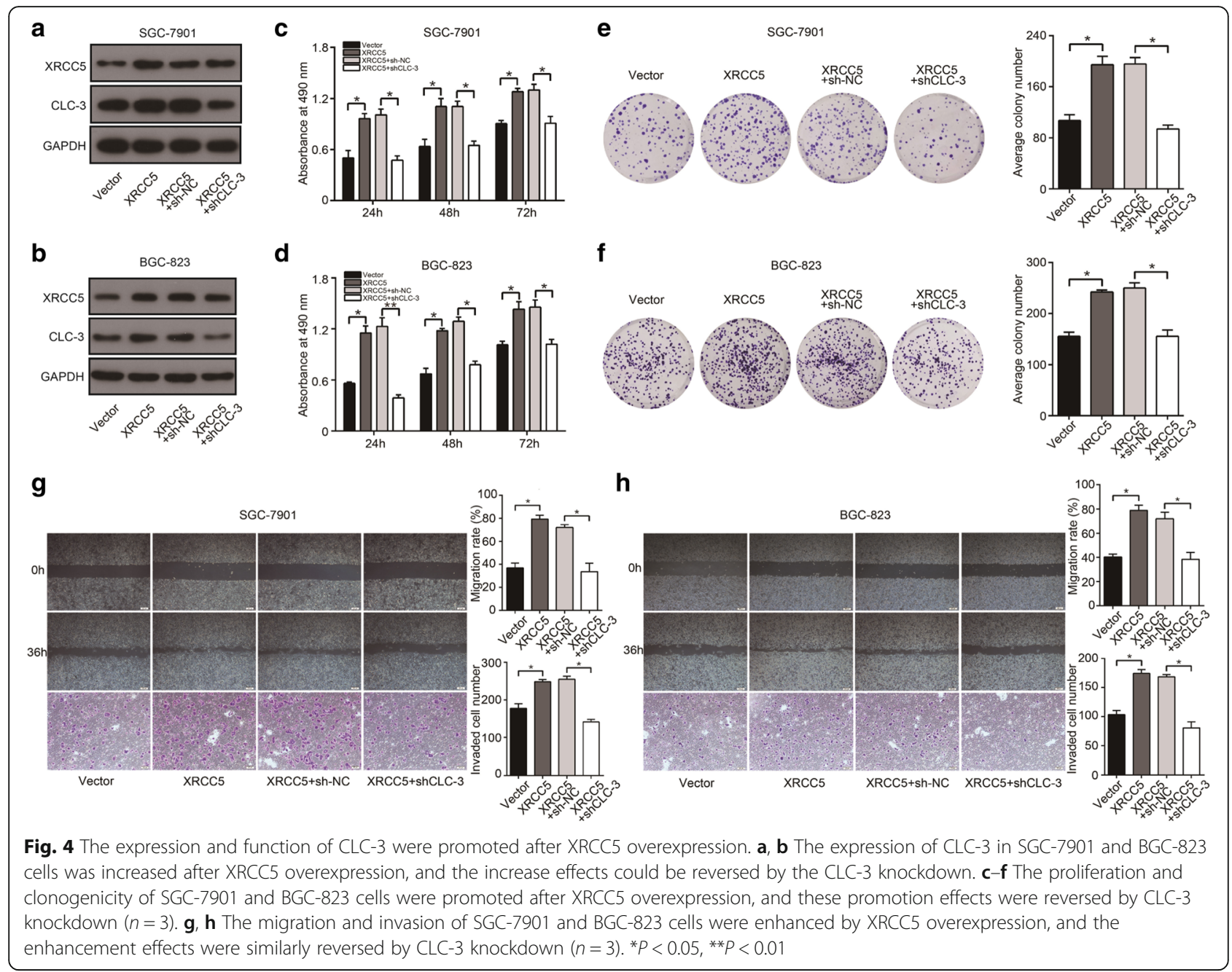

growth was inhibited after XRCC5 knockdown or CLC-3 knockdown. Conversely, overexpression of XRCC5 promoted tumor growth and the promotion effect could be reversed by CLC-3 knockdown (Fig. 6a-d). In addition, the expression of CLC-3 and XRCC5 in tumor tissues presented the same variation trend as tumor growth (Fig. 6e). These in vivo results were consistent with our in vitro observations and confirmed that CLC-3 could be regulated by XRCC5 in vivo.

\section{Discussion}

$\mathrm{GC}$ is one of the most common tumors and continues to be a serious public health problem in the clinic. To date, the prognosis of advanced GC patients remains poor. Consistently, the available targeted therapy clinical trials only target HER2 (trastuzumab) and VEGFR2 (ramucirumab) in advanced GC patients [25]. Therefore, there is a need to explore more potential biomarkers of GC for therapeutic purposes. Chloride channels are a new class of membrane proteins that are aberrantly expressed in multiple tumor types. In addition to regulating various aspects of cancer cell behavior, chloride channels may constitute promising cancer biomarkers. However, few studies have focused on exploiting chloride channels for clinical purposes in GC. In this study, we first found that CLC-3, a member of the voltage-gated chloride channel superfamily, was overexpressed in human GC tissues and GC cell lines, suggesting a possible pivotal role of CLC-3 overexpression in GC development. Importantly, high expression of CLC-3 predicted poor prognosis in GC patients, demonstrating that overexpression of $\mathrm{CLC}-3$ was a poor prognostic biomarker for GC.

CLC-3 is a crucial exchange transporter in plasma membranes and intracellular vesicles. Recently, the study of CLC-3 in cell metastasis and proliferation has attracted much attention [26-28]. Nonetheless, as a potential prognostic biomarker, the role of CLC-3 in digestive tract cancers is rarely reported, including GC. In this study, the primary biological functions of CLC-3 were identified as cell proliferation and migration, which were identical to the clinicopathological characteristics 


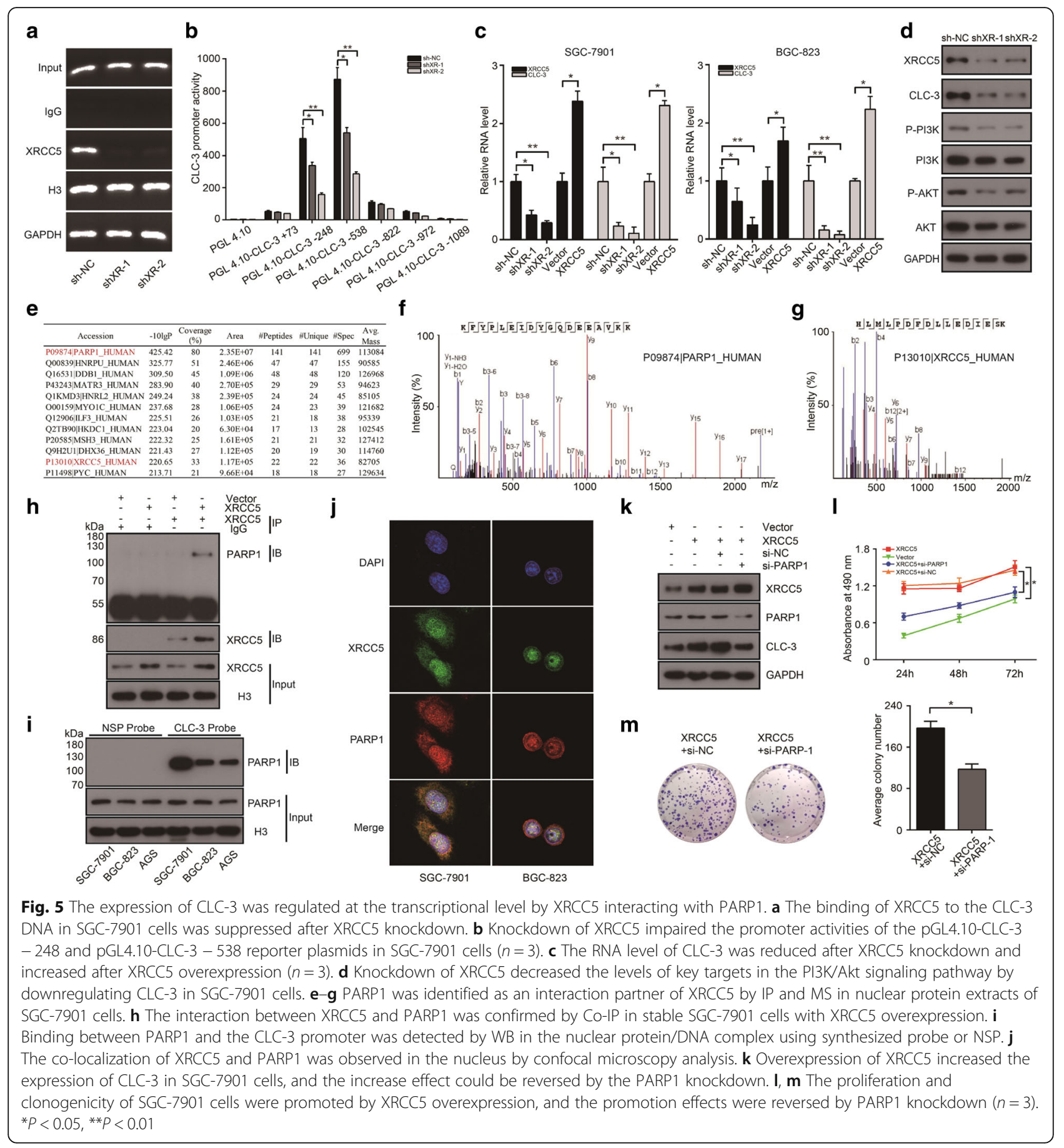

analysis of CLC-3 expression in GC patients, indicating that overexpression of CLC-3 in GC acted as a potential tumor-promoting factor by facilitating cell proliferation and migration. In addition, we found that the PI3K/Akt signaling pathway, a critical pathway mainly implicated in cell proliferation and migration [29, 30], was inhibited after the CLC-3 knockdown. This result was in accord with our previous finding indicating that the PI3K/Akt signaling pathway might be the downstream signaling pathway of CLC-3 [31]. So, we focused on the PI3K/ AKT pathway rather than other pathways, and we hypothesized that CLC-3 might regulate cell proliferation and migration via this pathway. Accordingly, as a prognostic biomarker for GC, CLC-3 also plays important roles in vitro. Investigating the molecular mechanism of CLC-3 overexpression in GC development is needed.

To further explore the molecular mechanism of CLC-3 overexpression in GC, we studied the basic RNA 


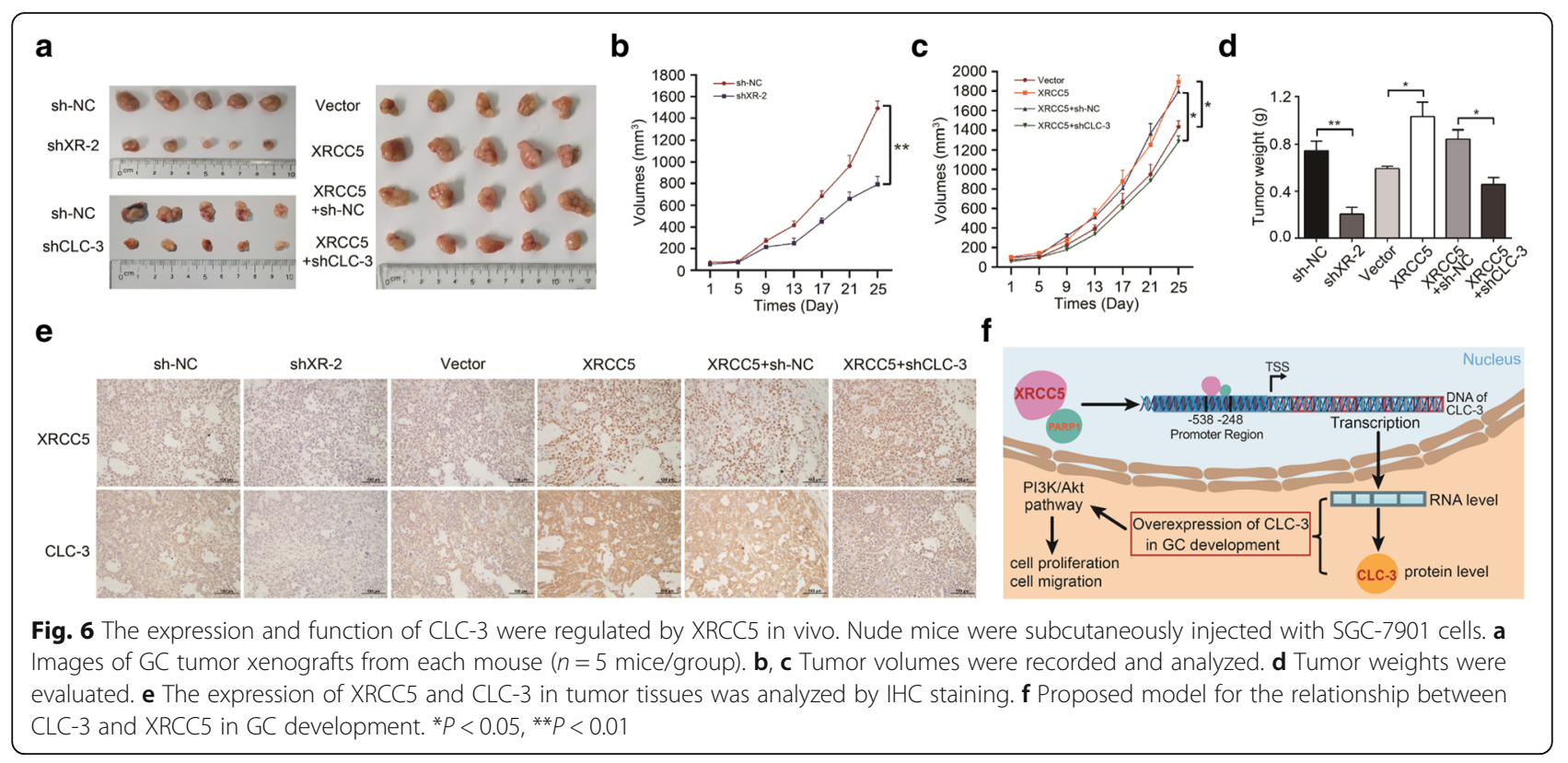

expression of CLC-3 in cell lines. Elevated RNA level was also observed in GC cell lines, suggesting that a specific transcriptional regulatory mechanism of CLC-3 overexpression might exist in GC. With the regulatory events often occurring at gene promoters, we speculated that some tumor-specific cellular factors might bind specifically to the CLC-3 promoter to upregulate CLC-3 expression. Therefore, an optimal promoter probe was synthesized to pull down CLC-3 promoter-binding proteins $[32,33]$. Our study demonstrated that XRCC5 bound the CLC-3 promoter, and increased combination was observed in GC cells, suggesting that this increased binding might be a promoting factor of CLC-3 overexpression. The novel finding of this study was the identification of XRCC5 as a CLC-3 promoter-binding protein in GC cells. To provide valuable clinical outcome prediction information, we then examined the expression of CLC-3 and XRCC5 in GC patients. Similar to most other types of tumors, the expression of XRCC5 in GC was also significantly increased [22-24]. Moreover, the expression of CLC-3 and XRCC5 presented the same variation trend, which was identified by their positive correlated expression in GC tissues. The survival analysis indicated that high expression of XRCC5 predicted poor prognosis in GC patients, prompting that XRCC5 might be a tumor-promoting factor in GC development. Importantly, the patients with high expression of XRCC5 and CLC-3 had the worst prognosis, revealing the synergistic effect of XRCC5 and CLC-3 on GC progression. Cox regression analysis further demonstrated that both CLC-3 and XRCC5 were prognostic factors of the overall survival in GC patients and that double detection of CLC-3 and XRCC5 could provide precise information for predicting the prognosis of GC patients. These findings indicate that the expression of CLC-3 is elevated in GC tissues in response to increased XRCC5 levels, and double targeting of CLC-3 and XRCC5 may provide more useful therapeutic potential for GC treatment.

As the regulatory subunit of the DNA-dependent protein kinase complex DNA-PK, XRCC5 is associated with the development of tumors such as lung cancer, breast cancer, and bladder cancer [34-36]. Functionally, XRCC5 acts as a double-edged sword by inhibiting or promoting tumor progression in different tumor types $[37,38]$. However, little is known about the role of XRCC5 in GC. Clinicopathological characteristics analysis suggested that XRCC5 might promote the proliferation and invasion of GC cells. In vitro, the primary biological functions of CLC-3 were suppressed after XRCC5 knockdown and promoted after XRCC5 overexpression, reconfirming the tumor-promoting action of XRCC5. The rescue models with CLC-3 overexpression and reverse models with CLC-3 knockdown further certified that CLC-3 was the molecular target of XRCC5. Collectively, these results indicate that the expression and function of CLC-3 are regulated by XRCC5 in vitro and that XRCC5 is a tumor-promoting factor in GC. However, XRCC5 may not be the only regulator of CLC-3, and other molecular regulators can also exist in GC cells.

The above results only illustrated that XRCC5 bound to the CLC-3 promoter in the nucleus. To further verify the molecular mechanisms underlying the interaction between CLC-3 and XRCC5, ChIP assays and luciferase assays were performed in SGC-7901 cells with XRCC5 knockdown. We proved that knockdown of XRCC5 
suppressed the binding of XRCC5 to the CLC-3 DNA and impaired the promoter activity of the pGL4.10CLC-3 - 248 and pGL4.10-CLC-3 - 538 reporter plasmids, which indicated that the potential binding site might be located between -248 and -538 . Furthermore, the RNA level of CLC-3 was inhibited by XRCC5 knockdown and increased by XRCC 5 overexpression, validating that the expression of CLC-3 was regulated by XRCC5 at the transcriptional level. Next, XRCC5 knockdown inhibited the levels of key targets in the PI3K/Akt signaling pathway by downregulating CLC-3, confirming that the observed effects of XRCC5 on proliferation and migration were reflected at the functional level of CLC-3. Previous studies have indicated that XRCC5 binds the promoter region of genes such as pS2, FAS, and COX-2, thus regulating gene transcription. The XRCC5-interacting proteins identified in these genes' promoter regions include DNA-PK, XRCC6, PARP-1, topoisomerase II $\beta, \mathrm{PP} 1$, and p300 [19, 20, 37]. Therefore, we tested whether XRCC5 bound to the CLC-3 promoter by interacting with other proteins. PARP1, also known as poly (ADP-ribose) polymerase 1 , was discovered as a potential candidate for interaction with XRCC5 in the nucleus. Served as a transcription factor [39], PARP1 is essential for many cellular processes, including maintenance of genomic integrity, chromatin dynamics, and transcriptional regulation [40]. To ascertain whether PARP1 also bound the CLC-3 promoter, we pulled down the nuclear protein/DNA complex in GC cells using a CLC-3 promoter probe and validated their direct binding. We therefore speculated that PARP1 should also be identified in Fig. 2e. Nevertheless, the upper differential protein band (at almost $120 \mathrm{kDa}$ ) was not analyzed by MS. Previous studies have reported that PARP1 often forms regulatory complexes with other proteins and then regulates the expression of genes, including CCND1, CCN2, and NF-kB [41-43]. Indeed, the co-localization of XRCC5 and PARP1 was observed in the nucleus, indicating that XRCC5 and PARP1 formed a regulatory complex in the nucleus. It has been reported that PARP1 is overexpressed in GC and that PARP1 knockdown significantly attenuates the proliferation of GC cells $[44,45]$. Therefore, we preliminarily explored the interaction effect of PARP1 and XRCC5 on CLC-3 expression and cell proliferation. The results indicated that the promotion effect of XRCC5 overexpression on the CLC-3 expression and cell proliferation was partly reversed by the PARP1 knockdown, which suggested that PARP1 might act as a positive regulatory factor for CLC-3 in GC cells. These findings prove that knockdown of XRCC5 suppresses the binding of XRCC5 to the CLC-3 promoter and subsequent promoter activity, thus regulating CLC-3 expression at the transcriptional level by interacting with PARP1. Currently, there are ongoing clinical trials of many PARP1 inhibitors aimed at DNA binding and transcriptional activity [4648], and one PARP inhibitor, olaparib, has been approved by the FDA to treat ovarian cancer patients with BRCA genes mutations [49], providing new prospects for the application of this inhibitor in future studies.

The relationship between CLC-3 and XRCC5 was also investigated in mouse xenograft models. The results were consistent with our in vitro data and showed that CLC-3 could be regulated by XRCC5 in vivo. Here, we propose a model for the relationship between CLC-3 and XRCC5 in GC development (Fig. 6f). Overexpression of CLC-3 is a poor prognostic biomarker for GC, and CLC-3 may regulate cell proliferation and migration via the PI3K/AKT signaling pathway. The regulatory mechanism of CLC-3 overexpression in GC is that XRCC5 binds the CLC-3 promoter region and affects subsequent promoter activity, thus regulating CLC-3 expression at the transcriptional level by interacting with PARP1.

\section{Conclusions}

In summary, this study has illustrated that overexpression of CLC-3 is regulated by XRCC5 and is a poor prognostic biomarker for gastric cancer. Double targeting CLC-3 and XRCC5 may provide promising therapeutic potential for GC treatment.

\section{Additional file}

Additional file 1: Table S1. The truncated promoter regions of CLC-3 were designed with primer pairs as follows. (DOCX 29 kb)

\section{Abbreviations}

ANT: Adjacent normal tissues; BSA: Bovine serum albumin; cDNA: Complementary DNA; ChIP: Chromatin immunoprecipitation; Cl: Confidence interval; CLC-3: Chloride channel-3; Co-IP: Coimmunoprecipitation; DAB: 3,5-Diaminobenzidine; DAPI: 4,6-Diamidino-2phenylindole; DGE: Differential gene expression; DNA-PK: DNA-dependent protein kinase; FBS: Fetal bovine serum; GC: Gastric cancer; GO: Gene Ontology; HR: Hazard rate; IF: Immunofluorescence; IHC: Immunohistochemistry; IP: Immunoprecipitation; KEGG: Kyoto Encyclopedia of Genes and Genomes; MS: Mass spectrometry; MTS: 3-(4,5Dimethylthiazol-2-yl)-5-(3-carboxymethoxyphenyl)-2-(4-sulfophenyl)-2 $\mathrm{H}$ tetrazolium; NSP: Nonspecific probe; OD: Optical density; PAGE: Polyacrylamide gel electrophoresis; PARP1: Poly (ADP-ribose) polymerase 1; PBS: Phosphate-buffered solution; PCR: Polymerase chain reaction; PVDF: Polyvinylidene fluoride; qRT-PCR: Quantitative real-time polymerase chain reaction; RPMI: Roswell Park Memorial Institute; SDS: Sodium dodecyl sulfate; SRA: Sequence Read Archive; WB: Western blot; XRCC5: X-ray repair cross-complementing 5

\section{Funding}

This work was supported by the funds from the National Natural Science Foundation of China $(81272223,81273539)$, the Ministry of Education of China (20124401110009), the Natural Science Foundation of Guangdong Province (2016A030313495), and the Science and Technology Programs of Guangdong (2017A050501021, 2013B051000059). 


\section{Availability of data and materials}

The datasets used and/or analyzed during the current study are available from the corresponding author on reasonable request.

\section{Authors' contributions}

ZG and YL conceived and designed the study. YL collected GC samples and clinical information. $Z G, Y L$, and $X Y$ performed the experiments and acquired the result data. $M Y, Z C$, and $C Z$ helped to perform the partial experiments and review the statistical analysis. ZG and YL drafted the manuscript. LC and LW critically revised the manuscript and supervised the study. All authors read and approved the final manuscript.

\section{Ethics approval and consent to participate}

All animal procedures were performed following the Guide for the Care and Use of Laboratory Animals and the Institutional Ethical Guidelines for Animal Experiments developed by Jinan University. All patients' samples were collected after informed consent in accordance with the Declaration of Helsinki, and the study was approved by the Ethics Committee of Zhengzhou University.

\section{Consent for publication}

Not applicable

\section{Competing interests}

The authors declare that they have no competing interests.

\section{Publisher's Note}

Springer Nature remains neutral with regard to jurisdictional claims in published maps and institutional affiliations.

\section{Author details}

'Department of Pharmacology, Medical College, Jinan University, Guangzhou 510632, China. ${ }^{2}$ Department of Pathophysiology, Medical College, Jinan University, Guangzhou, China. ${ }^{3}$ Department of Clinical Oncology, The First Affiliated Hospital, Zhengzhou University, Zhengzhou, China. ${ }^{4}$ Department of Physiology, Medical College, Jinan University, Guangzhou 510632, China.

Received: 21 June 2018 Accepted: 31 August 2018

\section{Published online: 14 September 2018}

\section{References}

1. Van Cutsem E, Sagaert X, Topal B, Haustermans K, Prenen H. Gastric cancer. Lancet. 2016;388:2654-64.

2. Badgwell B, Das P, Ajani J. Treatment of localized gastric and gastroesophageal adenocarcinoma: the role of accurate staging and preoperative therapy. J Hematol Oncol. 2017;10:149.

3. Ferlay J, Soerjomataram I, Dikshit R, Eser S, Mathers C, Rebelo M, Parkin DM, Forman D, Bray F. Cancer incidence and mortality worldwide: sources, methods and major patterns in GLOBOCAN 2012. Int J Cancer. 2015;136: E359-86.

4. Zheng L, Wang L, Ajani J, Xie K. Molecular basis of gastric cancer development and progression. Gastric Cancer. 2004;7:61-77.

5. Zhang XW, Sheng YP, Li Q, Qin W, Lu YW, Cheng YF, Liu BY, Zhang FC, Li J, Dimri GP, Guo WJ. BMI1 and Mel-18 oppositely regulate carcinogenesis and progression of gastric cancer. Mol Cancer. 2010;9:40.

6. Wang X, Wang C, Zhang X, Hua R, Gan L, Huang M, Zhao L, Ni S, Guo W. Bmi-1 regulates stem cell-like properties of gastric cancer cells via modulating miRNAs. J Hematol Oncol. 2016;9:90

7. Gan L, Xu M, Hua R, Tan C, Zhang J, Gong Y, Wu Z, Weng W, Sheng W, Guo $W$. The polycomb group protein EZH2 induces epithelial-mesenchymal transition and pluripotent phenotype of gastric cancer cells by binding to PTEN promoter. J Hematol Oncol. 2018;11:9.

8. Fan Y, Wang YF, Su HF, Fang N, Zou C, Li WF, Fei ZH. Decreased expression of the long noncoding RNA LINC00261 indicate poor prognosis in gastric cancer and suppress gastric cancer metastasis by affecting the epithelialmesenchymal transition. J Hematol Oncol. 2016;9:57.

9. Jentsch TJ, Pusch M. CLC chloride channels and transporters: structure, function, physiology, and disease. Physiol Rev. 2018;98:1493-590.

10. Habela CW, Olsen ML, Sontheimer H. ClC3 is a critical regulator of the cell cycle in normal and malignant glial cells. J Neurosci. 2008;28:9205-17.
11. Cuddapah VA, Turner KL, Seifert S, Sontheimer H. Bradykinin-induced chemotaxis of human gliomas requires the activation of $\mathrm{KCa} 3.1$ and $\mathrm{ClC}-3$. J Neurosci. 2013;33:1427-40.

12. Lemonnier L, Shuba Y, Crepin A, Roudbaraki M, Slomianny C, Mauroy B, Nilius B, Prevarskaya N, Skryma R. BCl-2-dependent modulation of swellingactivated $\mathrm{Cl}^{-}$current and $\mathrm{ClC}-3$ expression in human prostate cancer epithelial cells. Cancer Res. 2004;64:4841-8.

13. Zhu L, Yang H, Zuo W, Yang L, Zhang H, Ye W, Mao J, Chen L, Wang L. Differential expression and roles of volume-activated chloride channels in control of growth of normal and cancerous nasopharyngeal epithelial cells. Biochem Pharmacol. 2012;83:324-34.

14. Mao J, Chen L, Xu B, Wang L, Li H, Guo J, Li W, Nie S, Jacob TJ, Wang L. Suppression of $\mathrm{ClC}-3$ channel expression reduces migration of nasopharyngeal carcinoma cells. Biochem Pharmacol. 2008;75:1706-16.

15. Mao J, Yuan J, Wang L, Zhang H, Jin X, Zhu J, Li H, Xu B, Chen L. Tamoxifen inhibits migration of estrogen receptor-negative hepatocellular carcinoma cells by blocking the swelling-activated chloride current. J Cell Physiol. 2013; 228:991-1001.

16. Mao J, Chen L, Xu B, Wang L, Wang W, Li M, Zheng M, Li H, Guo J, Li W, et al. Volume-activated chloride channels contribute to cell-cycledependent regulation of HeLa cell migration. Biochem Pharmacol. 2009;77: 159-68.

17. Taccioli GE, Gottlieb TM, Blunt T, Priestley A, Demengeot J, Mizuta R, Lehmann AR, Alt FW, Jackson SP, Jeggo PA. Ku80: product of the XRCC5 gene and its role in DNA repair and V(D)J recombination. Science. 1994;265: 1442-5.

18. Gottlieb TM, Jackson SP. The DNA-dependent protein kinase: requirement for DNA ends and association with Ku antigen. Cell. 1993;72:131-42.

19. Ju BG, Lunyak W, Perissi V, Garcia-Bassets I, Rose DW, Glass CK, Rosenfeld MG. A topoisomerase Ilbeta-mediated dsDNA break required for regulated transcription. Science. 2006;312:1798-802.

20. Wong RH, Chang I, Hudak CS, Hyun S, Kwan HY, Sul HS. A role of DNA-PK for the metabolic gene regulation in response to insulin. Cell. 2009;136: 1056-72.

21. Trinh $B Q, K o S Y$, Barengo N, Lin SY, Naora $H$. Dual functions of the homeoprotein DLX4 in modulating responsiveness of tumor cells to topoisomerase II-targeting drugs. Cancer Res. 2013;73:1000-10.

22. Moeller BJ, Yordy JS, Williams MD, Giri U, Raju U, Molkentine DP, Byers LA, Heymach JV, Story MD, Lee JJ, et al. DNA repair biomarker profiling of head and neck cancer: Ku80 expression predicts locoregional failure and death following radiotherapy. Clin Cancer Res. 2011;17:2035-43.

23. Grabsch H, Dattani M, Barker L, Maughan N, Maude K, Hansen O, Gabbert $H E$, Quirke P, Mueller W. Expression of DNA double-strand break repair proteins ATM and BRCA1 predicts survival in colorectal cancer. Clin Cancer Res. 2006;12:1494-500.

24. Ma Q, Li P, Xu M, Yin J, Su Z, Li W, Zhang J. Ku80 is highly expressed in lung adenocarcinoma and promotes cisplatin resistance. J Exp Clin Cancer Res. 2012;31:99.

25. Tan P, Yeoh KG. Genetics and molecular pathogenesis of gastric adenocarcinoma. Gastroenterology. 2015;149:1153-62. e1153

26. Guan $Y T$, Huang $Y Q$, Wu JB, Deng ZQ, Wang $Y$, Lai ZY, Wang HB, Sun $X X$, Zhu YL, Du MM, et al. Overexpression of chloride channel-3 is associated with the increased migration and invasion ability of ectopic endometrial cells from patients with endometriosis. Hum Reprod. 2016;31:986-98.

27. Qin C, He B, Dai W, Lin Z, Zhang H, Wang X, Wang J, Zhang X, Wang G, Yin $L$, Zhang $Q$. The impact of a chlorotoxin-modified liposome system on receptor MMP-2 and the receptor-associated protein CIC-3. Biomaterials. 2014;35:5908-20.

28. Zeng JW, Wang XG, Ma MM, Lv XF, Liu J, Zhou JG, Guan YY. Integrin beta3 mediates cerebrovascular remodelling through $\mathrm{Src} / \mathrm{ClC}-3$ volumeregulated $\mathrm{Cl}(-)$ channel signalling pathway. $\mathrm{Br}$ J Pharmacol. 2014;171: 3158-70.

29. Hennessy BT, Smith DL, Ram PT, Lu Y, Mills GB. Exploiting the PI3K/AKT pathway for cancer drug discovery. Nat Rev Drug Discov. 2005;4:988-1004.

30. Fu QF, Liu Y, Fan Y, Hua SN, Qu HY, Dong SW, Li RL, Zhao MY, Zhen Y, Yu $\mathrm{XL}$, et al. Alpha-enolase promotes cell glycolysis, growth, migration, and invasion in non-small cell lung cancer through FAK-mediated PI3KVAKT pathway. J Hematol Oncol. 2015:8:22

31. Liu J, Zhang D, Li Y, Chen W, Ruan Z, Deng L, Wang L, Tian H, Yiu A, Fan C, et al. Discovery of bufadienolides as a novel class of ClC-3 chloride channel activators with antitumor activities. J Med Chem. 2013;56:5734-43. 
32. Liu T, Li W, Lu W, Chen M, Luo M, Zhang C, Li Y, Qin G, Shi D, Xiao B, et al. RBFOX3 promotes tumor growth and progression via hTERT signaling and predicts a poor prognosis in hepatocellular carcinoma. Theranostics. 2017;7: 3138-54.

33. Huang R, Chen Z, He L, He N, Xi Z, Li Z, Deng Y, Zeng X. Mass spectrometry-assisted gel-based proteomics in cancer biomarker discovery: approaches and application. Theranostics. 2017;7:3559-72.

34. Lee MN, Tseng RC, Hsu HS, Chen JY, Tzao C, Ho WL, Wang YC. Epigenetic inactivation of the chromosomal stability control genes BRCA1, BRCA2, and XRCC5 in non-small cell lung cancer. Clin Cancer Res. 2007;13:832-8.

35. Pucci S, Mazzarelli P, Rabitti C, Giai M, Gallucci M, Flammia G, Alcini A, Altomare V, Fazio VM. Tumor specific modulation of KU70/80 DNA binding activity in breast and bladder human tumor biopsies. Oncogene. 2001;20: 739-47.

36. Wang S, Wang M, Yin S, Fu G, Li C, Chen R, Li A, Zhou J, Zhang Z, Liu O. A novel variable number of tandem repeats (VNTR) polymorphism containing Sp1 binding elements in the promoter of XRCC5 is a risk factor for human bladder cancer. Mutat Res. 2008;638:26-36.

37. Zhang Z, Zheng F, Yu Z, Hao J, Chen M, Yu W, Guo W, Chen Y, Huang W, Duan Z, Deng W. XRCC5 cooperates with p300 to promote cyclooxygenase2 expression and tumor growth in colon cancers. PLoS One. 2017;12: e0186900.

38. Wei S, Xiong M, Zhan DQ, Liang BY, Wang YY, Gutmann DH, Huang ZY, Chen XP. Ku80 functions as a tumor suppressor in hepatocellular carcinoma by inducing S-phase arrest through a p53-dependent pathway. Carcinogenesis. 2012;33:538-47.

39. Forrest AR, Kawaji H, Rehli M, Baillie JK, de Hoon MJ, Haberle V, Lassmann T, Kulakovskiy IV, Lizio M, Itoh $\mathrm{M}$, et al. A promoter-level mammalian expression atlas. Nature. 2014;507:462-70.

40. Schiewer MJ, Knudsen KE. Transcriptional roles of PARP1 in cancer. Mol Cancer Res. 2014;12:1069-80.

41. Shan L, Li X, Liu L, Ding X, Wang Q, Zheng Y, Duan Y, Xuan C, Wang Y, Yang F, et al. GATA3 cooperates with PARP1 to regulate CCND1 transcription through modulating histone $\mathrm{H} 1$ incorporation. Oncogene. 2014:33:3205-16.

42. Okada H, Inoue T, Kikuta T, Kato N, Kanno Y, Hirosawa N, Sakamoto Y, Sugaya T, Suzuki H. Poly(ADP-ribose) polymerase-1 enhances transcription of the profibrotic CCN2 gene. J Am Soc Nephrol. 2008;19:933-42.

43. Hassa PO, Haenni SS, Buerki C, Meier NI, Lane WS, Owen H, Gersbach M, Imhof R, Hottiger MO. Acetylation of poly(ADP-ribose) polymerase-1 by p300/CREB-binding protein regulates coactivation of NF-kappaB-dependent transcription. J Biol Chem. 2005;280:40450-64.

44. Park SH, Jang KY, Kim MJ, Yoon S, Jo Y, Kwon SM, Kim KM, Kwon KS, Kim CY, Woo HG. Tumor suppressive effect of PARP1 and FOXO3A in gastric cancers and its clinical implications. Oncotarget. 2015;6:44819-31.

45. Liu Y, Zhang Y, Zhao Y, Gao D, Xing J, Liu H. High PARP-1 expression is associated with tumor invasion and poor prognosis in gastric cancer. Oncol Lett. 2016;12:3825-35.

46. Hu X, Huang W, Fan M. Emerging therapies for breast cancer. J Hematol Oncol. 2017:10:98.

47. Dholaria B, Hammond W, Shreders A, Lou Y. Emerging therapeutic agents for lung cancer. J Hematol Oncol. 2016;9:138.

48. Laroche A, Chaire V, Le Loarer F, Algeo MP, Rey C, Tran K, Lucchesi C, Italiano A. Activity of trabectedin and the PARP inhibitor rucaparib in softtissue sarcomas. J Hematol Oncol. 2017;10:84.

49. Du Y, Yamaguchi H, Wei Y, Hsu JL, Wang HL, Hsu YH, Lin WC, Yu WH, Leonard PG, GRt L, et al. Blocking c-Met-mediated PARP1 phosphorylation enhances anti-tumor effects of PARP inhibitors. Nat Med. 2016;22:194-201.

\section{Ready to submit your research? Choose BMC and benefit from:}

- fast, convenient online submission

- thorough peer review by experienced researchers in your field

- rapid publication on acceptance

- support for research data, including large and complex data types

- gold Open Access which fosters wider collaboration and increased citations

- maximum visibility for your research: over $100 \mathrm{M}$ website views per year

At BMC, research is always in progress.

Learn more biomedcentral.com/submissions 